\title{
Outbreak investigation of SARS-CoV-2 transmission in an emergency childcare centre
}

\author{
Julio C. Soto ${ }^{1}$ (I) $\cdot$ Mireille Barakat $^{1} \cdot$ Juliana Ayres Hutter $^{1} \cdot$ Marilou Kiely $^{1} \cdot$ Sandrine Moreira $^{2} \cdot$ B. Jesse Shapiro ${ }^{3}$. \\ Carmen Lia Murall ${ }^{4}$ - Nicolas Parenteau ${ }^{5}$ • Joane Désilets ${ }^{5} \cdot$ Richard Lessard $^{5}$
}

Received: 22 February 2021 / Accepted: 11 May 2021 / Published online: 28 May 2021

(C) The Canadian Public Health Association 2021

\begin{abstract}
Objective To characterize SARS-CoV-2 transmission following a COVID-19 outbreak in an emergency childcare centre (ECCC) in April 2020 in Quebec, Canada.

Methods The study population consisted of all the children and employees who attended the ECCC as well as household contacts of the confirmed COVID-19 cases. Of the 120 individuals in the study, five cases were confirmed by epidemiological link and 25 were identified as COVID-19 by RT-PCR among which 19 were analyzed by viral whole genome sequencing. Descriptive epidemiology, social network visualization, and phylogenetic analysis were used to characterize viral transmission.

Results Phylogenetic analysis identified two separate introductions of distinct lineages of SARS-CoV-2 and estimated an average effective reproductive number of $R_{e}=1.9$ (range 0.9-4.9) with a mean doubling time of 3.2 days (range 2.1-5.2). The first and most prevalent lineage was introduced by two asymptomatic children who were likely infected by their parent, a confirmed COVID-19 case working in a long-term care centre. Among infected household adults, attack rates were significantly higher in mothers than in fathers (risk ratio $=4.5 ; 95 \%$ CI 1.1-18.7). The extent of transmission makes it one of the largest documented outbreaks in a daycare in Canada.

Conclusion The analyses carried out showed the probable origin and direction of the transmission of the infection (adult-child, child-adult, and child-child), thus highlighting how asymptomatic children can efficiently transmit SARS-CoV-2.
\end{abstract}

\section{Résumé}

Objectif Caractériser la transmission du SRAS-CoV-2 à la suite d'une éclosion de COVID-19 dans un service de garde d'urgence en milieu scolaire (SGUMS) en avril 2020 au Québec, Canada.

Julio C. Soto

julio.soto@inspq.qc.ca

Mireille Barakat

mireille.barakat@inspq.qc.ca

Juliana Ayres Hutter

juliana.ayres-hutter@inspq.qc.ca

Marilou Kiely

marilou.kiely@inspq.qc.ca

Sandrine Moreira

sandrine.moreira@inspq.qc.ca

B. Jesse Shapiro

jesse.shapiro@mcgill.ca

Carmen Lia Murall

carmenlia.murall@outlook.com

Nicolas Parenteau

nicolas.parenteau.drsp.ccsmtl@ssss.gouv.qc.ca
Joane Désilets

Joane.desilets.reg14@ssss.gouv.qc.ca

Richard Lessard

richard.lessard.cissslan@ssss.gouv.qc.ca

1 Direction des risques biologiques et de la santé au travail, Institut national de santé publique du Québec, 190 boul. Crémazie Est, Montréal, Québec H2P 1E2, Canada

2 Laboratoire de santé publique du Québec, Institut national de santé publique du Québec, Montréal, Québec, Canada

3 Department of Microbiology and Immunology, McGill University, Montréal, Québec, Canada

4 Département de sciences biologiques, Université de Montréal, Montréal, Québec, Canada

5 Direction de santé publique, Centre intégré de santé et de services sociaux de Lanaudière, Joliette, Québec, Canada 
Méthodes La population à l'étude était composée de tous les enfants et employés ayant fréquenté le SGUMS ainsi que les contacts familiaux des cas confirmés de COVID-19. Sur les 120 personnes à l'étude, cinq cas ont été confirmés par lien épidémiologique et 25 par RT-PCR. Parmi ces derniers, 19 ont été analysés par séquençage viral du génome entier. La caractérisation de la transmission a été réalisée à l'aide d'analyses descriptives et phylogénétiques ainsi que de la visualisation de réseaux sociaux.

Résultats L'analyse phylogénétique a identifié deux introductions de lignées distinctes du SRAS-CoV-2 et un taux de reproduction net $R_{e}=1,9$ (étendue 0,9-4,9) avec un temps moyen de doublement de 3,2 jours (étendue 2,1-5,2). La première lignée, et la plus répandue, a été introduite par deux enfants asymptomatiques qui ont probablement été infectés par leur parent, un travailleur de la santé atteint de COVID-19. Dans les noyaux familiaux, les taux d'attaque étaient significativement plus élevés chez les mères que chez les pères (rapport de risque $=4,5$; IC à $95 \%$ 1,1-18,7). L'ampleur de la transmission en fait de celle-ci la plus importante éclosion documentée dans un service de garde au Canada.

Conclusion Cette étude a permis de déterminer l'origine et la direction probables de la transmission de l'infection (adulte-enfant, enfant-adulte et enfant-enfant) et démontrer que les enfants asymptomatiques peuvent transmettre le SRAS-CoV-2.

Keywords COVID-19 · SARS-CoV-2 · Phylogenetic analysis · Children · Transmission · School $\cdot$ Daycare · Outbreak

Mots-clés COVID-19 · SARS-CoV-2 analyse phylogénétique $\cdot$ enfants $\cdot$ transmission · école $\cdot$ garderie $\cdot$ éclosion

\section{Introduction}

The severe acute respiratory syndrome coronavirus 2 (SARSCoV-2) was identified in the city of Wuhan, China, at the end of 2019. The World Health Organization declared the coronavirus disease (COVID-19) a public health emergency of international concern on January 30, 2020 and a global pandemic on March 11 (Organisation mondiale de la Santé, 2020). Multiple studies have aimed to characterize infection and transmission in children, with mixed results. Children under the age of 10 appear to be less clinically affected by COVID19 , even in the presence of high viral load and changes in pulmonary or serum biochemistry (Hu et al., 2020). At the beginning of the pandemic, cases of COVID-19 in children tended to have a history of exposure to a case in the family or in other adults (Ludvigsson, 2020; Zhu et al., 2020). However, they were rarely identified as index cases in domestic or other outbreaks, suggesting the limited potential for children to seed onward transmission (Kiely et al., 2020). Other studies have implicated children as source cases (Merckx et al., 2020), thus the role of children in the transmission of SARS-CoV-2 remains unclear.

Starting March 15, 2020, the province of Quebec, Canada, was under lockdown and schools and daycares were closed. Emergency childcare centres (ECCC) were made available for children whose parents are essential workers. The present study was carried out following the report of an outbreak of COVID-19 in an ECCC located in an administrative region of around 500,000 inhabitants. From its opening to the beginning of the outbreak, the service had been frequented by 50 children in total (with a mean of 20 children present each day, separated into two or three groups) and between 12 and 28 full- and part-time employees. As the number of children could differ each day, educators could be assigned to a different group of children each day. At the time of the outbreak investigation, which was still early in the first wave, public health recommendations for childcare workers in terms of protective measures such as the use of masks and face shields were not yet in use. Also, physical distancing was difficult to respect. Because this event constituted an opportune "hot spot" setting, public health authorities agreed to further investigate the outbreak to better understand the transmission dynamics of SARS-CoV-2 within the ECCC, to identify the probable source of introduction of the virus and the factors which favoured the development of the outbreak.

\section{Methods}

In our investigation, three approaches were used to characterize the outbreak: descriptive epidemiology, social network analysis (SNA), and phylogenetic analysis of viral genome sequences.

\section{Participants}

The study population included all children and employees who attended the ECCC for at least one day from April 9 until its closure on May 5 and family contacts of confirmed cases (extended to May 18 to ensure follow-up). A unique identifier was attributed to cases and contacts starting with a $\mathrm{C}$ for "child" and A for "adult" followed by E if they were associated with the ECCC, or H if they were from a household. For the purposes of the investigation, case definitions for confirmed and suspected cases were established for contacts as well (Fig. 1). Household contacts were monitored daily for symptoms and only symptomatic contacts were tested. 


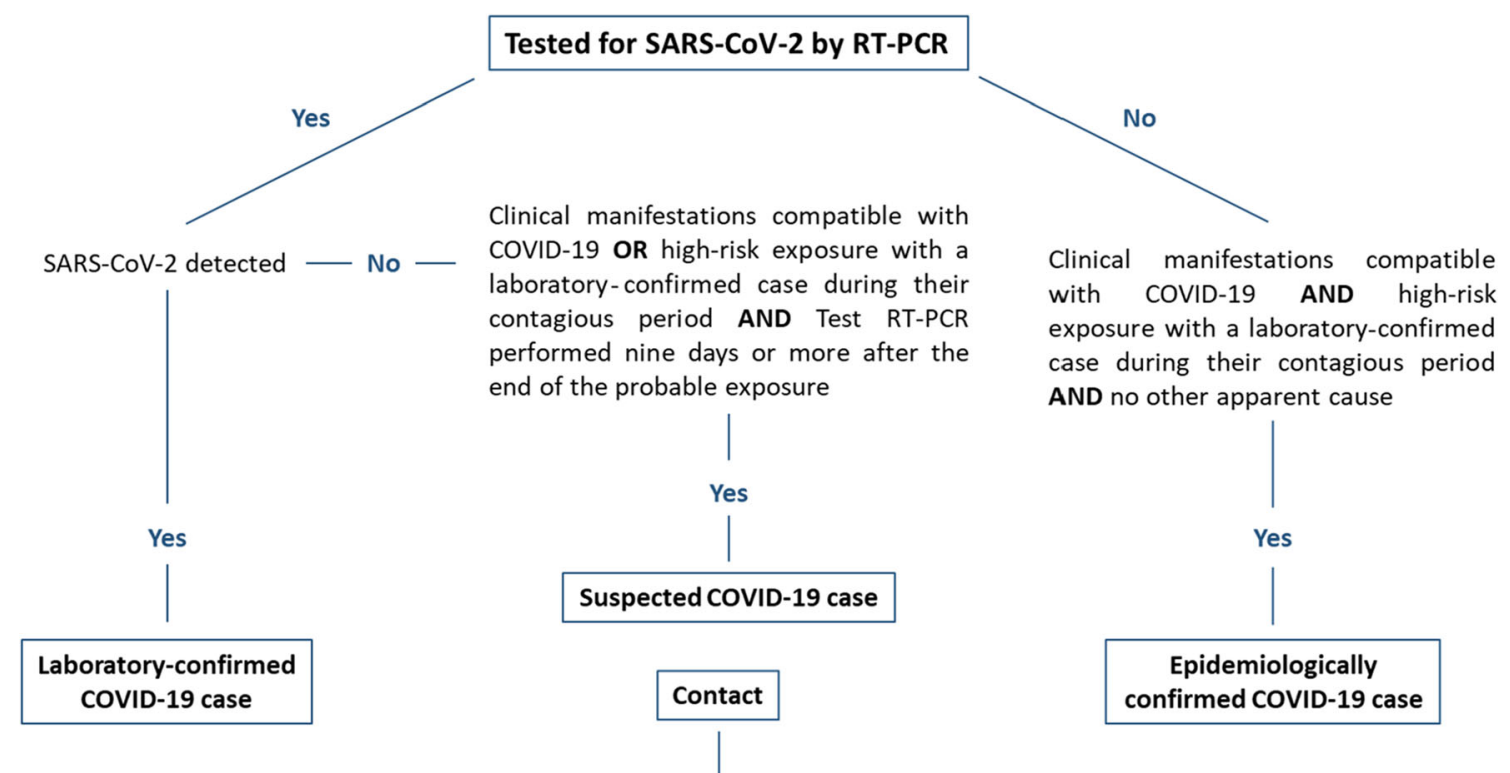

Any person living in the same household OR having had direct physical contact with a COVID-19 confirmed case AND who had a negative SARS-CoV-2 RT-PCR test OR refused screening AND not showing symptoms compatible with COVID-19

Fig. 1 Case definition algorithm. COVID-19 outbreak investigation, 9 April to 18 May 2020 (Institut national de santé publique du Québec, 2020; Kucirka et al., 2020; Ministère de la Santé et des Services sociaux, 2020)

\section{Procedures}

Diagnosis of COVID-19 was performed by RT-PCR; positive samples were referred to the Public Health Laboratory of Quebec (LSPQ) for confirmation. The epidemiological data were collected by the staff of the Regional Public Health Department (RPHD). Additional data collection was carried out by consulting the ECCC attendance records and by telephone interviews with adults and children who attended the ECCC. For SNA, household and ECCC components were characterized, and networks were visualized with the Pajek software v.5.08 (http://mrvar.fdv.uni-lj.si/pajek). For phylogenetic analyses, nucleic acids were extracted from nasopharyngeal specimens of cases, and reverse transcription was performed at the LSPQ. Full details of phylogenetic analyses and on parameter priors and MCMC (Markov chain Monte Carlo) implementation are in the Supplementary Materials (Table S1).

\section{Statistical analysis}

For continuous variables, mean values of confirmed cases and contacts were compared with a Student's $t$-test. Exploratory analyses of association between certain variables of interest were performed using the chi-square test of independence, or the exact mid- $p$ test when a chi-square statistic-predicted value was $<5$. Ninety-five percent confidence intervals were calculated to estimate the precision of the association measures studied. All statistical calculations were performed using
SPSS-PC version 25, or Open Source Epidemiological Statistics for Public Health (OpenEpi version 3.01). Missing data were excluded from analyses.

\section{Ethical issues}

This investigation was carried out in accordance with the legal mandate granted to public health authorities by Quebec's Public Health Act (LRQ, chapter S-2.2. Article 1) (Publications Québec, 2020) as part of a public health intervention. Interview participants (or legal guardians in the case of children) gave verbal consent at the time of the investigator's phone call, which was documented. All data were treated confidentially and analyzed without nominal identification in accordance with the Policy on Information Protection and Security (PO-04-2014) of the Institut national de santé publique du Québec.

\section{Results}

A total of 120 individuals participated in the investigation, 81 (68.1\%) of whom frequented or worked at the ECCC. Ninetythree people were tested by RT-PCR, and according to the case definitions, 25 were laboratory-confirmed COVID-19 cases, five were epidemiologically linked, and three were considered suspected cases. As expected for an ECCC-focused study, the ratio of children to adults among the 30 confirmed cases was 1.5. Table 1 also shows that the majority were 
Table 1 Characteristics of the study population. COVID-19 outbreak investigation, 9 April to 18 May 2020, Quebec, Canada

\begin{tabular}{|c|c|c|c|}
\hline & $\begin{array}{l}\mathrm{ECCC}^{1} \\
n(\%)\end{array}$ & $\begin{array}{l}\text { Household } \\
n(\%)\end{array}$ & $\begin{array}{l}\text { Total } \\
n(\%)\end{array}$ \\
\hline Total population & $81(68.1)$ & $39(31.9)$ & $120(100)$ \\
\hline Cases & $21(70)$ & $9(30)$ & $30(100)$ \\
\hline Contacts & $60(66.7)$ & $30(33.3)$ & $90(100)$ \\
\hline \multicolumn{4}{|l|}{ Age groups (years) } \\
\hline$\leq 5$ & $2(2.5)$ & $2(5.1)$ & $4(3.3)$ \\
\hline $6-10$ & $51(63.0)$ & $0(0.0)$ & $51(42.5)$ \\
\hline $11-17$ & $0(0.0)$ & $2(5.1)$ & $2(1.7)$ \\
\hline $18-39$ & $6(7.4)$ & $16(41.0)$ & $22(18.3)$ \\
\hline $40-59$ & $19(23.4)$ & $18(46.2)$ & $37(30.8)$ \\
\hline$\geq 60$ & $3(3.7)$ & $1(2.6)$ & $4(3.3)$ \\
\hline Children (2-15) & $53(65.4)$ & $4(10.3)$ & $57(47.5)$ \\
\hline Adults $(20-71)$ & $28(34.6)$ & $35(89.7)$ & $63(52.5)$ \\
\hline \multicolumn{4}{|l|}{ Sex } \\
\hline Female & $47(58)$ & $19(48.7)$ & $66(55)$ \\
\hline \multicolumn{4}{|l|}{ COVID-19 status } \\
\hline Total population tested ${ }^{2}$ & $73(78.5)$ & $20(21.5)$ & $93(100)$ \\
\hline SARS-CoV-2 detected ${ }^{2}$ & $19(26)$ & $6(30)$ & $25(26.9)$ \\
\hline Epidemiological link & $2(2.7)$ & $3(15)$ & $5(5.4)$ \\
\hline Suspected & $3(4.1)$ & 0 & $3(3.2)$ \\
\hline Total COVID-19 cases & $21(70)$ & $9(30)$ & $30(100)$ \\
\hline Children $(2-15)$ & $17(81)$ & $1(11.1)$ & $18(60)$ \\
\hline Adults $(20-71)$ & $4(19)$ & $8(88.9)$ & $12(40)$ \\
\hline Female & $10(47.6)$ & $6(66.7)$ & $16(53.3)$ \\
\hline Male & $11(52.4)$ & $3(33.3)$ & $14(46.7)$ \\
\hline
\end{tabular}

${ }^{1}$ ECCC, emergency childcare centre

${ }^{2}$ SARS-CoV-2 real-time RT-PCR test

children $(81.0 \%)$ and significantly more cases were present in the ECCC (70.0\%) than in households (30.0\%). No significant differences were observed when cases and contacts were compared according to their sex, age, and having frequented or not the ECCC (data not shown).

Overall, the attack rate for the outbreak was $25.0 \%$ (30/120). Among the 35 adults from households, 14 (40.0\%) worked in a healthcare setting, i.e., hospitals, long-term care centres (LTCC), or nursing homes. In households, there were also more cases among mothers $(6 / 12$ or $50.0 \%)$ than among fathers $(2 / 16$ or $11.1 \%)(p=0.04$, risk ratio $=4.5$, $95 \% \mathrm{CI}=1.1-18.7)$. Among the 30 confirmed cases, 22 $(73.3 \%)$ reported symptoms (11 adults and 11 children) either at initial investigation or at follow-up, and one adult and seven children were asymptomatic. The proportion of asymptomatic cases was approximately four times higher in children (38.9\%) than in adults $(9.1 \%)$, although the difference was not significant $(p=0.102)$. None of the cases required hospitalization and all were stable or recovered at follow-up, which was up to 24 days after closing (May 28).

Figure 2 illustrates the distribution of cases according to the date of symptoms onset, or the date of laboratory sampling for the eight asymptomatic cases. Figure S1 illustrates the estimated contagious periods of each case. The index case was declared on April 28, 4 days after the onset of symptoms. Two adult cases were identified with a date of symptoms onset before the index case. The first was a healthcare worker working in a LTCC where an outbreak of COVID-19 was underway. This person started their symptoms on April 16 and had two children who attended the ECCC on April 16 and 17. Although the children both tested negative for SARS-CoV2 , they were classified as suspected cases because the test was performed 3 weeks after their parent's onset of symptoms. A

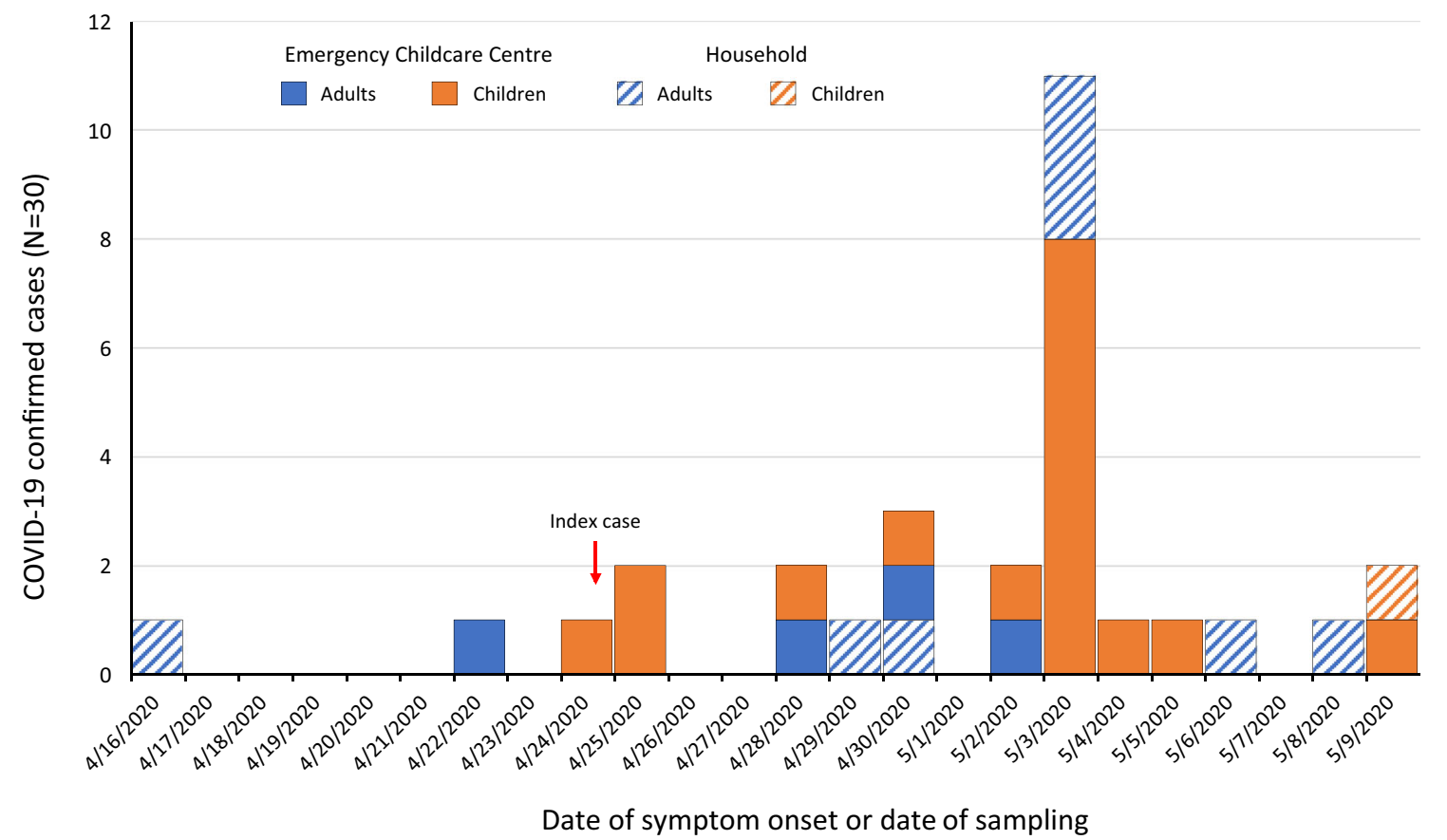

Fig. 2 Cases by date of illness onset or date of laboratory sampling. COVID-19 outbreak investigation, 9 April to 18 May 2020 
second adult case, an educator at the ECCC, started their symptoms while at work on April 22. The educator was absent on April 23 and 24 and returned to work on April 27. The number of cases increased from April 24 with a peak of 11 new cases on May 3, which corresponds to the referral for the diagnostic tests for anyone present at the ECCC on April 23 and 24. Cases were first detected in the ECCC attendees and then in their households.

To better characterize the transmission of the infection within the ECCC, exposure to days where suspected and infected cases were present at the centre was assessed. First, exposure to the ECCC on April 16 and 17 was assessed for the 81 individuals who attended the centre and were tested. The two suspected children (CE029 and CE030) attended the centre on those two dates before beginning isolation at home. A significantly higher proportion of cases attended the ECCC on those dates than ECCC contacts, $71.4 \%$ and $26.7 \%$, respectively $(p=0.0002)$. Second, exposure to the ECCC during the contagious period of the index case (April 23 and 24) was assessed. A significantly higher proportion of cases attended the ECCC on these days than ECCC contacts, $90.5 \%$ and $33.3 \%$, respectively $(p<0.0001)$. Finally, on average, cases (both children and adults) attended the ECCC more days than contacts. Child cases attended the ECCC for a mean of 11.2 days while contacts attended the ECCC for a mean of 5.2 days. Adult cases attended the ECCC for a mean of 12.8 days while contacts attended the ECCC for a mean of 3.9 days (respectively $p<0.0001$ and $p<0.001$ ).

Among the 25 individuals who tested positive for SARSCoV-2, specimens from 21 cases were sent to the LSPQ, of which 19 were sequenced (two specimens were of too low quality). Figure 3 illustrates the phylogenetic trees (of genetic distance and based on sampling dates) of these 19 viruses, and shows the alignment of specific point mutations that distinguish the genomes. All sequenced genomes belong to clade 20B according to the Nextstrain (Hadfield et al., 2018) nomenclature and clade B.1.1 in the Pangolin nomenclature (Cov-lineages/pangolin. [Python]. https://github.com/covlineages/pangolin (original work published 2020)) (Rambaut et al., 2020). Two sub-lineages were evident based on phylogenetic clustering. The first (cluster A) was composed of 10 individuals, including the healthcare worker with the earliest symptoms onset date (AH028), and the second (cluster B) of only two individuals which differed from cluster A by four single nucleotide variants. Cluster A contained additional variants, whereas both cluster $B$ sequences were identical. SARSCoV-2 evolves at a rate of $\sim 1.1 \times 10^{-3}$ mutations/site/year (Duchene et al., 2020; Rambaut et al., 2020), which corresponds to roughly one mutation every 11 days. Since the outbreak took place over a period of about a single month, we would therefore expect to observe approximately 2.7 mutations by chance in related cases. The genetic diversity within cluster $\mathrm{A}$ is thus consistent with evolution occurring during the ECCC outbreak, whereas the 4 mutations that separate clusters A and B suggest a common ancestor before the beginning of the ECCC outbreak (Fig. 3A). There were therefore most likely two separate introductions at the ECCC. The closure of the daycare likely stopped the second introduction from spreading further.

Two siblings (CE020 and CE021) sampled at the same time were found to have viral genomes that differed by one mutation (black squares in Fig. 3). This complicates the possibility of sibling-to-sibling transmission because, while a de novo mutation in one sibling (before sampling) is possible,
A

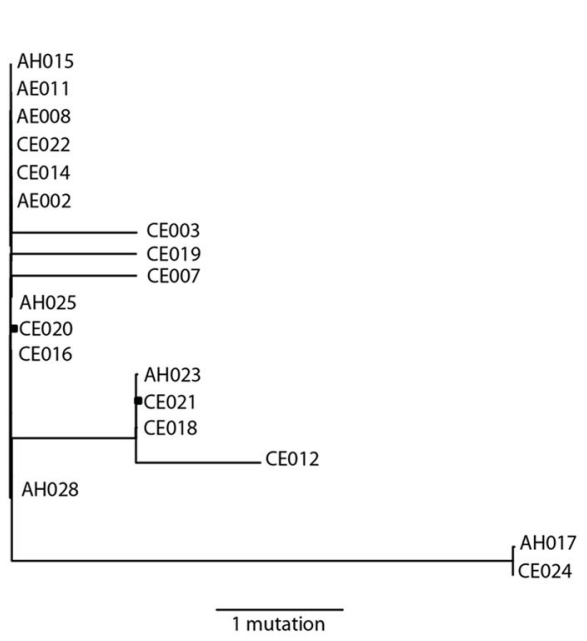

Fig. 3 Phylogenetic trees of SARS-CoV-2 genomes from the ECCC outbreak. A Neighbour-joining tree showing genetic distance between genomes. B Time-scaled maximum clade credibility tree, built using

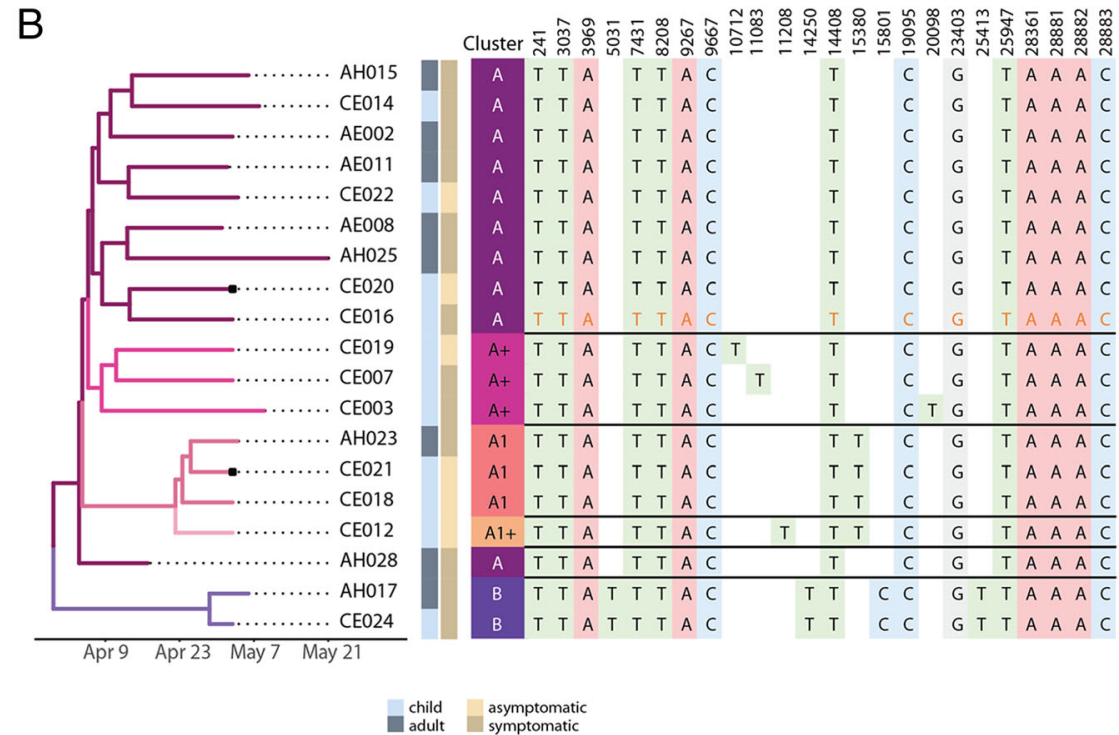

sampling dates. Branches are coloured based on phylogenetic cluster designation. Black squares annotate the two siblings who were sampled at the same time, but with different viral genome sequences 
three other cases also shared this mutation (cluster A1 or A1+) at the same sampling time. Without clear epidemiological links (and more sequences prior to May 3), other explanations such as infection of the siblings by different individuals or by a single individual with a mixed infection cannot be ruled out.

Finally, phylodynamic analyses of the viral genomes allowed for the estimation of key epidemiological parameters of the outbreak. The mean time to the most recent common ancestor (tMRCA) of the entire outbreak was estimated to be March 19 (95\% HPD: Feb. 15-April 10), which further suggests two introduction events because cluster $\mathrm{A}$ and $\mathrm{B}$ diverged before the outbreak occurred. The mean effective reproduction number for the outbreak was estimated to be 1.9 (95\% HPD: 0.9-4.9) and its variation over time is shown in the supplementary material in Fig. 6. The generation interval (i.e., the doubling time) was found to be 3.2 days (95\% HPD: 2.1-5.2 days) if using the symptoms dates or only cluster A and its nested variants (i.e., a single transmission chain). When using sampling dates and all viral genomes (including both transmission chains of clusters $\mathrm{A}$ and $\mathrm{B}$ ), the doubling time was 5.9 days (95\% HPD: 4.2-10 days; Fig. 7 in supplementary material). These values are similar to those found by previous SARS-CoV-2 studies (Ganyani et al., 2020).

The social network in Fig. 4 illustrates the 30 cases of COVID-19 represented by nodes (circles) and the edges (lines) between them depict family ties. A total of 18 families were associated with the ECCC outbreak and transmission within the household occurred in six of the families (average of 1.7 cases generated by each family). The first case shown in the network (AH028 with variant profile A) was the parent of the two children considered as suspected cases (CE029 and CE030) because they both attended the ECCC during her contagious period. The second adult case (AE002), who developed symptoms prior to the index case (CE001), was also carrying the A variant. The other suspected case (CE042) shown in the network was a child who attended the ECCC with 12 confirmed cases, but only got tested 12 days after he first started at the daycare. One of his parents was also a confirmed case but was asymptomatic.

\section{Discussion}

To date, this outbreak is the largest observed in Quebec in a childcare centre, with an attack rate of $25.0 \%$. Face masks combined with other preventive measures, such as frequent hand washing and physical distancing, were not applied regularly or even possible. With what is currently known about the transmission of SARS-CoV-2, this likely contributed to the large number of cases. The number of cases $(n=30)$ is similar to another outbreak seen in June 2020 at a childcare centre in Oregon, USA, with 28 cases (Oregon Health Authority, 2020). The symptoms observed both in children and adults in the ECCC outbreak are similar to those observed in other studies (Meena et al., 2020).

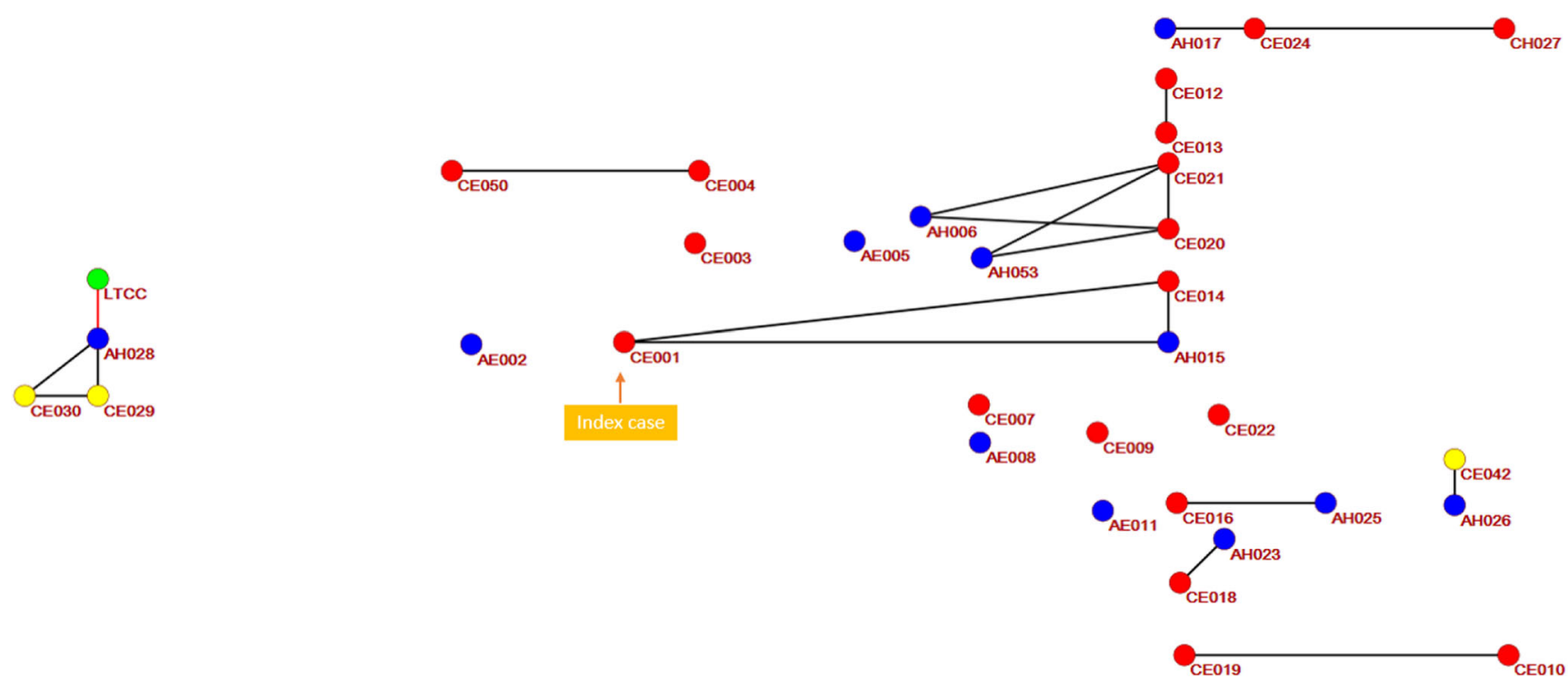

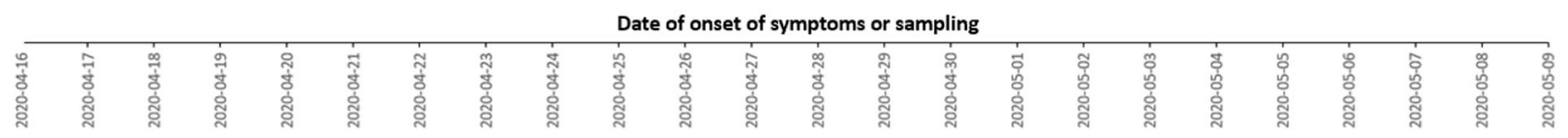

Fig. 4 Social network of COVID-19 cases by date of symptom onset or sampling. Node (circle) colour: Blue is for adults, red is for children, and yellow is for cases who were classified as suspected because they were not tested or tested too late after exposure. Green illustrates the workplace. Edge (line) colours: Black depicts family ties between cases and red is for the workplace ties 
In the ECCC, the four infected workers attended the centre for longer periods than their uninfected counterparts, suggesting that a longer exposure time could lead to a higher risk of transmission. The observed attack rate for staff was similar or higher $(14.3 \%)$ to those seen in other studies where no secondary cases were attributed to contagious children attending school (Heavey et al., 2020; Stein-Zamir et al., 2020). Meanwhile, seroprevalence surveys of schools have been largely inconclusive. A study carried out in a primary school found no secondary cases following the attendance of three contagious cases before the school was closed (Fontanet et al., 2020a). However, two other studies have shown a much higher proportion of seropositivity among staff. The first, in a high school, showed a seropositivity prevalence of $43.4 \%$ among educators and 59.3\% among non-educators (Fontanet et al., 2020b). The second, with students ranging from preschool to high school, showed that $20.6 \%$ of educators and $7.1 \%$ of non-educators were seropositive (Torres et al., 2020).

In the outbreak described here, the number of people infected among household cases remained limited due to, among other things, the size of families. Notably, mothers appeared to be more affected than fathers. This suggests that mothers, if they tend to be primary childcare providers, are at higher risk of being infected.

Children are rarely reported as index cases of household clusters. It is therefore difficult to compare the secondary attack rate in families seen in the present outbreak with those seen elsewhere. Some publications report secondary attack rates between $4.0 \%$ and $10.2 \%$ in children, and between $11.2 \%$ and $17.1 \%$ in adults (Bi et al., 2020; Fontanet et al., 2020a). However, it is very difficult to identify the direction of transmissions involving children as they are often asymptomatic and thus the point at which the child has acquired the infection is unknown.

SNA allowed us to better understand the connections between the cases and contacts, as well as the importance of certain individuals in the network. Regarding the source of the outbreak, phylogenetic analyses support two independent introduction events of SARS-CoV-2 (cluster A and cluster B) into the ECCC. The earliest identified case, carrying a virus from cluster $\mathrm{A}$, is the parent of the two children suspected of having introduced the infection into the ECCC on April 16 and 17. This person is a healthcare worker at a LTCC that was experiencing an outbreak at the time, and was likely contagious as of April 14. The first case carrying the cluster B variant is also the parent of a child attending the ECCC. This person worked in a private nursing home where several COVID-19 cases had been identified. Based on the date of symptom onset (May 5) and phylogenetic analyses, one of their children attending the ECCC likely acquired the infection from them (cluster B). The ECCC closed on the same day, explaining why we did not observe any further infections with the cluster B variant.
With respect to the direction and dynamics of the infection, the three methodological approaches used in the study were complementary and made it possible to better characterize the outbreak. Genome sequencing and phylogenetic analysis showed that, as expected, most individuals from the same family share the same genetic variants. The exception was a pair of siblings with different genetic variants, suggesting other transmission scenarios besides sibling-to-sibling transmission. The determination of the genetic variants in relation to the dates of symptom onset made it possible, in some cases, to make hypotheses about the direction of transmission. Three directions of transmission are apparent in our outbreak analysis: adult-to-child, child-to-adult, and child-to-child. Notably, no adult-to-adult transmissions were inferred. One adult-to-child transmission event resulted in the introduction of one of the viral variants into the ECCC, i.e., the transmission from parent to child for which phylogenetic analyses were conclusive (cluster B), with the infection being limited to these two cases. Three events of child-toadult transmission were documented and corroborated by phylogenetic analysis. Three children were infected at the ECCC (all from cluster A and related variants), and then transmitted the infection to their parents. Of these, two children were symptomatic, and one was asymptomatic. Although the sample size is relatively small, the results show that SARS-CoV-2 transmission events involving children are possible. Finally, phylogenetic analysis showed that transmission between children occurred at least once. The child with the A1 + variant likely acquired the infection from one of the two other children with the $\mathrm{A} 1$ variant. However, there could be non-sampled intermediaries.

Previous studies suggest children's contribution to the spread of SARS-CoV-2 is limited as compared with adults (Rajmil, 2020). However, most of these studies were performed in a lockdown context where contact was limited, thus masking any effects that children might have on transmission. Investigations in schools have tended to show low transmission rates (Heavey et al., 2020; Yung et al., 2020). However, available studies (Bi et al., 2020; Li et al., 2020; Posfay-Barbe et al., 2020) suggest that children are just as susceptible to SARSCoV-2 infection as adults and that, even in the absence of symptoms, they can transmit it (Li et al., 2021; Ludvigsson, 2020; Posfay-Barbe et al., 2020; Zhu et al., 2020). A more recent study from Wuhan showed that children who were secondary cases were more likely to infect household members who were in contact with them during their infectious period (Li et al., 2021). Furthermore, according to results from the Netherlands National Institute for Public Health and the Environment, the virus is largely transmitted between individuals of the same age (National Institute for Public Health and the Environment, 2020). More recently in India, a study revealed a high infection prevalence in contacts of children of the same age, speculating that transmission of the infection may happen during peer-to-peer interactions (Laxminarayan et al., 2020). Similar conclusions may be surmised from the present study. 
As in any observational study, several limitations should be highlighted. The investigation started while the outbreak was still active and the study population only included confirmed cases and their contacts. Although a follow-up was done among the children and educators who tested negative for SARS-CoV-2, not all household contacts were investigated. Also, at the time of the investigation, the public health directive was to request diagnostic tests only for symptomatic household contacts, thereby potentially underestimating the number of confirmed cases linked to the ECCC. Despite the small sample size, we still observed significant differences in exposures between cases and contacts. Another limitation was the delay in testing for some people. Three suspected cases were tested up to a month after the date of onset of their relatives' symptoms (Sethuraman et al., 2020). In addition, a few individuals refused to get tested. Serological tests would have allowed quantifying the underestimation, but they were not available in Quebec at the time of study. Finally, phylogenetic analyses are limited in resolution due to the relative lack of genetic diversity in SARS-CoV-2 over weekly time scales. Moreover, we were unable to sequence all cases. It is therefore possible that intermediate links in the chain of transmission were missed. Taking these into consideration, the present study cannot be generalized to other outbreaks and the general population.

\section{Conclusion}

Our case study demonstrates how SARS-CoV-2 can be transmitted from healthcare workers to their children, and then from children to other adults or children in their daycare or household. Spread by asymptomatic children highlights the importance of rapid action after the detection of an index case, and of implementing other preventive measures. Our study emphasizes how viruses can be introduced multiple times independently into a given setting, especially when community transmission is high. We also suggest that mothers, and possibly other primary caregivers, might be at higher risk of acquiring the transmission from children. More broadly, our findings can help guide case and contact management, future prevention and control measures, and epidemiological investigations in childcare settings.

\section{Contributions to knowledge and practice}

What does this study add to existing knowledge?

- Multiple introductions whether simultaneous or successive can happen and may be likely in a context of high community transmission.

- Both symptomatic and asymptomatic children transmitted SARS-CoV-2 to their parents and other children.
- The infection can be transmitted rapidly from healthcare settings into childcare centres and schools.

- An integrated investigative approach allowed the local, regional, and provincial health authorities to work together to achieve an effective and timely outbreak communication among all parties.

What are the key implications for public health interventions, practice or policy?

- The operational challenges encountered in the field offered an opportunity to adapt and innovate methods and tools, giving the experience a better perspective for investigating future outbreaks.

- These findings, together with available literature, suggest that schools and childcare centres should be closely monitored for cases and potential outbreaks.

- This evidence should be considered when drafting new policies and official guidelines concerning SARS-CoV2 , so as not to minimize the role played by children in the transmission of the disease.

- Sharing this experience can guide case and contact management, future prevention and control measures, and epidemiological investigations in childcare settings.

Supplementary Information The online version contains supplementary material available at https://doi.org/10.17269/s41997-021-00544-1.

Acknowledgements The authors would like to thank the following members of the Institut national de santé publique du Québec (INSPQ) who helped in the outbreak investigation as participant investigators: Marion Ripoche, Julie Ducrocq, Sandie Briand (scientific counseling and data collection); and as technical administrative supporters: Linda Cléroux and Mélissa Trudeau (writing assistance and data editing). We would also like to thank the team from the local health authority involved in the investigation and management of the outbreak and all staff, parents, and children of the childcare centre, without whom this study would not have been possible. Finally, we are grateful to Dr. Bryn William-Jones for his assistance with ethical issues.

Author contributions Conceptualization: JCS, MB, and JAH; methodology: JCS, MB, JAH, SM, BJS, and CLM; data curation: MB, JAH, MK, SM, BJS, CLM, NP, and JD; epidemiological and social network analysis: JCS, MB, JAH, and MK; phylogenetic analysis: SM, BJS, and CLM; writing — original draft: JCS, MB, and JAH; writing — review and editing: all authors; accountability, supervision, and integrity: JCS, RL, and JD.

Data availability Not applicable.

Code availability Not applicable.

\section{Declarations}

Ethics approval Not applicable.

Consent to participate Not applicable. 
Consent for publication Not applicable.

Conflict of interest The authors declare that they have no competing interests.

\section{References}

Bi, Q., Wu, Y., Mei, S., Ye, C., Zou, X., Zhang, Z., Liu, X., Wei, L., Truelove, S. A., Zhang, T., Gao, W., Cheng, C., Tang, X., Wu, X., Wu, Y., Sun, B., Huang, S., Sun, Y., Zhang, J., et al. (2020). Epidemiology and transmission of COVID-19 in 391 cases and 1286 of their close contacts in Shenzhen, China: A retrospective cohort study. The Lancet. Infectious Diseases. https://doi.org/10. 1016/S1473-3099(20)30287-5.

Duchene, S., Featherstone, L., Haritopoulou-Sinanidou, M., Rambaut, A., Lemey, P., \& Baele, G. (2020). Temporal signal and the phylodynamic threshold of SARS-CoV-2. BioRxiv, 2020.05.04.077735. https://doi.org/10.1101/2020.05.04.077735.

Fontanet, A., Grant, R., Tondeur, L., Madec, Y., Grzelak, L., Cailleau, I., Ungeheuer, M.-N., Renaudat, C., Fernandes Pellerin, S., Kuhmel, L., Staropoli, I., Anna, F., Charneau, P., Demeret, C., Bruel, T., Schwartz, O., \& Hoen, B. (2020a). SARS-CoV-2 infection in primary schools in northern France: A retrospective cohort study in an area of high transmission [Preprint]. Infectious Diseases (except HIV/AIDS). https://doi.org/10.1101/2020.06.25.20140178. Accessed 20 April 2021.

Fontanet, A., Tondeur, L., Madec, Y., Grant, R., Besombes, C., Jolly, N., Pellerin, S. F., Ungeheuer, M.-N., Cailleau, I., Kuhmel, L., Temmam, S., Huon, C., Chen, K.-Y., Crescenzo, B., Munier, S., Demeret, C., Grzelak, L., Staropoli, I., Bruel, T., ... Hoen, B. (2020b). Cluster of COVID-19 in northern France: A retrospective closed cohort study. MedRxiv, 2020.04.18.20071134. https://doi. org/10.1101/2020.04.18.20071134. Accessed 20 April 2021.

Ganyani, T., Kremer, C., Chen, D., Torneri, A., Faes, C., Wallinga, J., \& Hens, N. (2020). Estimating the generation interval for coronavirus disease (COVID-19) based on symptom onset data, March 2020. Eurosurveillance, 25(17), 2000257. https://doi.org/10.2807/15607917.ES.2020.25.17.2000257.

Hadfield, J., Megill, C., Bell, S. M., Huddleston, J., Potter, B., Callender, C., Sagulenko, P., Bedford, T., \& Neher, R. A. (2018). Nextstrain: Real-time tracking of pathogen evolution. Bioinformatics, 34(23), 4121-4123. https://doi.org/10.1093/bioinformatics/bty407.

Heavey, L., Casey, G., Kelly, C., Kelly, D., \& McDarby, G. (2020). No evidence of secondary transmission of COVID-19 from children attending school in Ireland, 2020. Eurosurveillance, 25(21), 2000903. https://doi.org/10.2807/1560-7917.ES.2020.25.21. 2000903.

Hu, Z., Song, C., Xu, C., Jin, G., Chen, Y., Xu, X., Ma, H., Chen, W., Lin, Y., Zheng, Y., Wang, J., Hu, Z., Yi, Y., \& Shen, H. (2020). Clinical characteristics of 24 asymptomatic infections with COVID19 screened among close contacts in Nanjing, China. Science China. Life Sciences, 63(5), 706-711. https://doi.org/10.1007/s11427-0201661-4.

Institut national de santé publique du Québec. (2020). COVID-19. Formation : gestion des cas et des contacts. https://www.inspq.qc. ca/covid-19/formations/gestion-cas-contacts. Accessed 20 April 2021.

Kiely, M., Ducrocq, J., Talbot, D., Gilca, V., \& Sauvageau, C. (2020). Revue rapide de la littérature scientifique-COVID-19 chez, les enfants : facteurs de risque d'infections sévères et potentiel de transmission (p. 9). Institut national de santé publique du Québec. https://www.inspq.qc.ca/sites/default/files/covid/3007- enfants-risques-infections-transmission-covid19.pdf. Accessed 20 April 2021.

Kucirka, L. M., Lauer, S. A., Laeyendecker, O., Boon, D., \& Lessler, J. (2020). Variation in false-negative rate of reverse transcriptase polymerase chain reaction-based SARS-CoV-2 tests by time since exposure. Annals of Internal Medicine. https://doi.org/10.7326/ M20-1495.

Laxminarayan, R., Wahl, B., Dudala, S. R., Gopal, K., Mohan, C., Neelima, S., Reddy, K. S. J., Radhakrishnan, J., \& Lewnard, J. A. (2020). Epidemiology and transmission dynamics of COVID-19 in two Indian states. Science. https://doi.org/10.1126/science.abd7672.

Li, X., Xu, W., Dozier, M., He, Y., Kirolos, A., \& Theodoratou, E. (2020). The role of children in transmission of SARS-CoV-2: A rapid review. Journal of Global Health, 10(1). https://doi.org/10. 7189/jogh.10.011101.

Li, F., Li, Y.-Y., Liu, M.-J., Fang, L.-Q., Dean, N. E., Wong, G. W. K., Yang, X.-B., Longini, I., Halloran, M. E., Wang, H.-J., Liu, P.-L., Pang, Y.-H., Yan, Y.-Q., Liu, S., Xia, W., Lu, X.-X., Liu, Q., Yang, Y., \& Xu, S.-Q. (2021). Household transmission of SARS-CoV-2 and risk factors for susceptibility and infectivity in Wuhan: A retrospective observational study. The Lancet Infectious Diseases, 21(5), 617-628. https://doi.org/10.1016/S1473-3099(20)30981-6.

Ludvigsson, J. F. (2020). Children are unlikely to be the main drivers of the COVID-19 pandemic - A systematic review. Acta Paediatrica (Oslo, Norway: 1992), 109(8), 1525-1530. https://doi.org/10.1111/ apa.15371.

Meena, J., Yadav, J., Saini, L., Yadav, A., \& Kumar, J. (2020). Clinical features and outcome of SARS-CoV-2 infection in children: A systematic review and meta-analysis. Indian Pediatrics, 57(9), 820 826.

Merckx, J., Labrecque, J. A., \& Kaufman, J. S. (2020). Transmission of SARS-CoV-2 by children. Deutsches Ärzteblatt International, 117(33-34), 553-560. https://doi.org/10.3238/arztebl.2020.0553.

Ministère de la Santé et des Services sociaux. (2020). Coronavirus (COVID-19)_Professionnels de la santé-MSSS. https://www. msss.gouv.qc.ca/professionnels/maladies-infectieuses/coronavirus2019-ncov/\#definition-de-cas. Accessed 20 April 2021.

National Institute for Public Health and the Environment. (2020). Children, school and COVID-19. Ministry of Health, Welfare and Sport. https://www.rivm.nl/en/novel-coronavirus-covid-19/ children-and-covid-19. Accessed 20 April 2021.

Oregon Health Authority. (2020). Oregon's Weekly Surveillance Summary, Novel Coronavirus (COVID-19). July 1, 2020, p.14. https://www.oregon.gov/oha/PH/DISEASESCONDITIONS/ DISEASESAZ/Emerging\%20Respitory\%20Infections/COVID-19Weekly-Report-2020-07-01-FINAL.pdf. Accessed 20 April 2021.

Organisation mondiale de la Santé. (2020). Chronologie de l'action de l'OMS face à la COVID-19. https://www.who.int/fr/news-room/ detail/29-06-2020-covidtimeline. Accessed 20 April 2021.

Posfay-Barbe, K. M., Wagner, N., Gauthey, M., Moussaoui, D., Loevy, N., Diana, A., \& L'Huillier, A. G. (2020). COVID-19 in children and the dynamics of infection in families. Pediatrics, 146, e20201576. https://doi.org/10.1542/peds.2020-1576.

Publications Québec. (2020). Public Health Act, CQLR chapter S-2.2. http://legisquebec.gouv.qc.ca/en/ShowDoc/cs/S-2.2. Accessed 27 April 2021.

Rajmil, L. (2020). Role of children in the transmission of the COVID-19 pandemic: A rapid scoping review. BMJ Paediatrics Open, 4(1), e000722. https://doi.org/10.1136/bmjpo-2020-000722.

Rambaut, A., Holmes, E. C., Hill, V., O’Toole, Á., McCrone, J., Ruis, C., du Plessis, L., \& Pybus, O. G. (2020). A dynamic nomenclature proposal for SARS-CoV-2 to assist genomic epidemiology [Preprint]. Microbiology. http://biorxiv.org/lookup/doi/10.1101/ 2020.04.17.046086. Accessed 20 April 2021. 
Sethuraman, N., Jeremiah, S. S., \& Ryo, A. (2020). Interpreting diagnostic tests for SARS-CoV-2. JAMA, 323(22), 2249. https://doi.org/10. 1001/jama.2020.8259.

Stein-Zamir, C., Abramson, N., Shoob, H., Libal, E., Bitan, M., Cardash, T., Cayam, R., \& Miskin, I. (2020). A large COVID-19 outbreak in a high school 10 days after schools' reopening, Israel, May 2020. Eurosurveillance, 25(29), 2001352. https://doi.org/10.2807/15607917.ES.2020.25.29.2001352.

Torres, J. P., Piñera, C., De La Maza, V., Lagomarcino, A. J., Simian, D., Torres, B., Urquidi, C., Valenzuela, M. T., \& O'Ryan, M. (2020). SARS-CoV-2 antibody prevalence in blood in a large school community subject to a Covid-19 outbreak: A cross-sectional study. Clinical Infectious Diseases. https://doi.org/10.1093/cid/ciaa955.

Yung, C. F., Kam, K., Nadua, K. D., Chong, C. Y., Tan, N. W. H., Li, J., Lee, K. P., Chan, Y. H., Thoon, K. C., \& Ng, K. C. (2020). Novel coronavirus 2019 transmission risk in educational settings. Clinical Infectious Diseases. https://doi.org/10.1093/cid/ciaa794.

Zhu, Y., Bloxham, C. J., Hulme, K. D., Sinclair, J. E., Tong, Z. W. M., Steele, L. E., Noye, E. C., Lu, J., Chew, K. Y., Pickering, J., Gilks, C., Bowen, A. C., \& Short, K. R. (2020). Children are unlikely to have been the primary source of household SARS-CoV-2 infections (SSRN Scholarly Paper ID 3564428). Social Science Research Network. https://papers.ssrn.com/abstract=3564428. Accessed 20 April 2021.

Publisher's note Springer Nature remains neutral with regard to jurisdictional claims in published maps and institutional affiliations. 